\title{
A comparison of EuroQol 5-Dimension health- related utilities using Italian, UK, and US preference weights in a patient sample
}

This article was published in the following Dove Press journal:

ClinicoEconomics and Outcomes Research

13 June 2016

Number of times this article has been viewed

\author{
Adelaide Mozzi' \\ Michela Meregaglia ${ }^{2}$ \\ Carlo Lazzaro ${ }^{3}$ \\ Valentina Tornatore ${ }^{4}$ \\ Maurizio Belfiglio ${ }^{4}$ \\ Giovanni Fattore ${ }^{1,2}$ \\ 'Department of Policy Analysis and \\ Public Management, ${ }^{2}$ Centre for \\ Research on Health and Social Care \\ Management (CeRGAS), Bocconi \\ University, ${ }^{3}$ Studio di Economia \\ Sanitaria, Milan, ${ }^{4} \mathrm{AbbVie} \mathrm{srl,}$ \\ Campoverde Di Aprilia, Latina, Italy
}

\begin{abstract}
Weights associated with the EuroQol 5-Dimension 3-Level (EQ-5D-3L) instrument represent preferences for health states elicited from general population's samples. Weights have not been calculated for every country; however, empirical research shows that cross-country differences exist. This empirical study aims at investigating the impact of recently developed Italian weights in comparison with UK and US scores on health-related utility calculation using a sample of patients with Crohn's disease. The study is based on a survey on health-related quality of life in patients ( $\mathrm{n}=552)$ affected by active Crohn's disease conducted in Italy from 2012 to 2013 . Utilities computed through the Italian algorithm (mean: 0.76; SD: 0.20; median: 0.81 ) are generally higher than US (mean: 0.69; SD: 0.22; median: 0.77) and UK (mean: 0.57; SD: 0.32; median: 0.69) utilities, except for extremely severe health states where US values outweigh the Italian ones. UK preference weights generate the highest number of negative results. All the three value distributions are left-skewed due to very low scores associated with the most serious health states (ie, three or four levels equal to 3 ). As expected, despite the tariff set considered, more severe disease (Harvey Bradshaw Index $>16$ ) reduces the mean conditional EQ-5D-3L index $(P<0.0001)$. Kendall's rank correlation between EQ Visual Analog Scale score and EQ-5D-3L index is positive $(P<0.0001)$, even though patients tend to value their healthrelated quality of life more when responding to EQ-5D-3L questions than on EQ Visual Analog Scale. Regardless of the tariff set considered, ordinary least-square results highlight that more severe disease (Harvey Bradshaw Index $>16$ ) reduces the mean conditional EQ-5D-3L index $(P<0.0001)$. Results reveal remarkable differences among the three national tariff sets and especially when severe health states occur, suggesting the need for country-specific preference weights when evaluating utilities, which can be problematic since they have not been calculated for every country yet.
\end{abstract}

Keywords: EQ-5D, preference weights, utility values, VAS, Crohn's disease

\section{Introduction}

Modern medicine rapidly advances and, as a consequence, a huge number of new and expensive medical treatments become available. In a context in which national health care systems need to reduce their spending while improving people's health and health-related quality of life (HRQoL), economic evaluations of health care programs are becoming increasingly important.

Currently, the EuroQol 5-Dimension 3-Level (EQ-5D-3L) questionnaire is one of the most adopted instruments to measure HRQoL (also known as utility) in patient groups or general population. ${ }^{1,2}$ Utility is a prerequisite for calculation of qualityadjusted life-years (QALYs).
Correspondence: Adelaide Mozzi Department of Policy Analysis and Public Management, Bocconi University, Via Sarfatti 25, 20100 Milan, Italy Tel +39349I774773

Email adelaide.mozzi@gmail.com
(C) (7) (9) 2016 Mozi et al. This work is published and licensed by Dove Medical Press Limited. The full terms of this license are available at https://www.dovepress.com/terms.
php and incorporate the Creative Commons Attribution - Non Commercial (unported, v3.0) License (http://creativecommons.org/licenses/by-ncl3.0/). By accessing the work BY NC php and incorporate the Creative Commons Attribution - Non Commercial (unported, v3.0) License (http:///creativecommons.org/licenses//by-nc/3.0/). By accessing the
you hereby accept the Terms. Non-commercial uses of the work are permitted without any further permission from Dove Medical Press Limited, provided the work is properly attributed. For permission for commercial use of this work, please see paragraphs 4.2 and 5 of our Terms (https://www.dovepress.com/terms.php).
(a) 
The EQ-5D instrument is composed of two tools: a descriptive system and a Visual Analog Scale (VAS).

The EQ-5D-3L descriptive system allows the subject to report her/his health state with respect to five dimensions (mobility, self-care, usual activities, pain/discomfort, and anxiety/depression). Each dimension has three severity levels: 1 (no problem), 2 (some problems), or 3 (severe problems). There are $\left(3^{5}=243\right)$ possible health states that derive from the combination of the severity levels for each dimension (from 11111 to 33333 representing the best and the worst health state, respectively); two more health states, such as "unconscious" and "dead" are considered for an overall number of 245. An algorithm enables the researcher to compute a final score (ie, utility index) ranging from minus infinity to 1 by attributing specific weights to each health state.

With the EQ VAS, the subject scores her/his health state between 0 (the worst imaginable health state) and 100 (the best imaginable health state) on a $20 \mathrm{~cm}$-long, vertically oriented graphic graduated scale.

Weights associated with EQ-5D-3L represent preferences for health states elicited from samples of the general population through different techniques (ie, time trade-off, VAS). ${ }^{3}$

Preference weights have not yet been calculated for every country. Until recently, as many other developed countries, Italy has adopted UK weights. However, empirical research shows that cross-country differences exist, even when the same study protocol is applied ${ }^{4}$ and/or the sampled population data are adjusted for demographic differences. ${ }^{5}$ These differences are often reconducted to cultural issues and may have relevant effects on QALYs calculation and, thus, on priority setting in health care.

Up to now, a few studies have compared the impact of different country-based preference weights on given patient populations. A literature search in PubMed (keywords: "health utility", "preference weight", and "EQ-5D") performed on September 10, 2014, yielded only three studies on this topic: a comparison of UK, US, and Danish utilities in south Swedish patients with rheumatoid arthritis, ${ }^{6}$ a comparison of utility weights for pneumococcal and human papillomavirus diseases in Argentina, Chile, and UK, ${ }^{7}$ and a comparison of EQ-5D-3L index using UK, US, and Japan preference weights in a sample of Thai patients with type 2 diabetes. ${ }^{8}$ To the best of our knowledge, no research of this kind has been conducted in Italy so far.

This study aims at filling this gap by estimating the impact of three different country-specific (Italy, UK, and US) EQ-5D preference weights on the health utilities of a convenience sample ${ }^{9}$ of Italian patients with Crohn's disease (CD).
$\mathrm{CD}$ is a gastrointestinal chronic condition affecting about 100,000 individuals in Italy, with an incidence of approximately three to four new cases per 100,000 inhabitants per year. ${ }^{10}$ The peak age of Crohn's onset is $20-25$ years, ${ }^{10}$ which, combined with low fatality, means that patients live with the disease for decades experiencing substantial HRQoL impairment and financial burden. ${ }^{11}$

\section{Methods Study sample}

The study is based on a survey on HRQoL (Survey on Quality of Life in Crohn's Patients, SOLE) that was carried out in Italy from 2012 to 2013.

SOLE has been conducted on a large cohort of patients $(n=552)$ with active $C D$ to assess disease activity and its relationship with various aspects, such as workability, patient satisfaction, and compliance with the treatment.

Patients enrolled in SOLE survey were referred to a convenience sample ${ }^{9}$ of 38 Italian gastroenterological centers at the forefront in dealing with $\mathrm{CD}$ during four per protocol visits that were spaced out in a time frame of 1 year.

For the purpose of this study, only $500 \mathrm{EQ}-5 \mathrm{D}-3 \mathrm{~L}$ questionnaires and 497 EQ VAS collected during the first visit were included in the analysis.

As per SOLE survey's inclusion criteria, only adult patients ( $>18$ years) affected by moderate or severe CD (Harvey Bradshaw Index $[\mathrm{HBI}] \geq 8$ ) were eligible for the study. ${ }^{12}$ HBI quantifies CD activity according to five dimensions: general well-being, abdominal pain, number of liquid stools per day, abdominal mass, and further complications. A score of $<5$ is usually considered clinical remission. Scores between 5 and 7 represent a mild level of disease, whereas scores between 8 and 16 indicate a moderate burden. Scores $>16$ are symptomatic of severe disease.

SOLE study obtained approval/authorization by the ethics committees ("Comitati Etici", one per clinical center involved in the study), as requested by local regulations. Prior to the inclusion in the study, all patients in each center provided to the principal investigator a signed informed consent form for personal data treatment.

\section{Italian, UK, and US preference weights}

EQ-5D-3L indexes have been calculated by applying Italian, ${ }^{4} \mathrm{US},{ }^{13}$ and $\mathrm{UK}^{14}$ general population-based preference weights. Preferences for the scoring function were measured using the time trade-off technique on adults randomly sampled from the general population. ${ }^{3}$ The scoring function was obtained as coefficients of econometric models. ${ }^{3}$ 
Table I Italian, UK, and US algorithms used for EQ-5D-3L index calculation

\begin{tabular}{|c|c|c|c|c|}
\hline Variable & Definition & $\begin{array}{l}\text { Italian } \\
\text { model }\end{array}$ & $\begin{array}{l}\text { UK } \\
\text { model }\end{array}$ & $\begin{array}{l}\text { US } \\
\text { mode }\end{array}$ \\
\hline Constant & At least one level at 2 or 3 & NA & 0.081 & NA \\
\hline \multicolumn{5}{|l|}{ Mobility } \\
\hline Level 2 & Mobility at level 2 & 0.076 & 0.069 & 0.146 \\
\hline Level 3 & Mobility at level 3 & 0.518 & 0.314 & 0.558 \\
\hline \multicolumn{5}{|l|}{ S-C } \\
\hline Level 2 & S-C at level 2 & 0.100 & 0.104 & 0.175 \\
\hline Level 3 & S-C at level 3 & 0.289 & 0.214 & 0.471 \\
\hline \multicolumn{5}{|l|}{ UA } \\
\hline Level 2 & UA at level 2 & 0.085 & 0.036 & 0.140 \\
\hline Level 3 & UA at level 3 & 0.198 & 0.094 & 0.374 \\
\hline \multicolumn{5}{|l|}{ P/D } \\
\hline Level 2 & P/D at level 2 & 0.098 & 0.123 & 0.173 \\
\hline Level 3 & P/D at level 3 & 0.334 & 0.386 & 0.537 \\
\hline \multicolumn{5}{|l|}{$\mathrm{A} / \mathrm{D}$} \\
\hline Level 2 & A/D at level 2 & 0.095 & 0.071 & 0.156 \\
\hline Level 3 & A/D at level 3 & 0.213 & 0.236 & 0.450 \\
\hline N3 & Any dimension at level 3 & NA & 0.269 & NA \\
\hline DI & $\begin{array}{l}\text { Number of dimensions at level } 2 \\
\text { or } 3 \text { beyond the first }\end{array}$ & -0.043 & NA & -0.140 \\
\hline 13 & $\begin{array}{l}\text { Number of dimensions at level } 3 \\
\text { beyond the first }\end{array}$ & NA & NA & -0.122 \\
\hline 13-squared & Square of 13 & NA & NA & -0.015 \\
\hline 12-squared & $\begin{array}{l}\text { Square of number of dimensions } \\
\text { at level } 2 \text { beyond the first }\end{array}$ & NA & NA & 0.011 \\
\hline
\end{tabular}

Notes: The constant term is a number which is subtracted when there is a shift away from the perfect health status (IIIII). N3 is a dummy variable assuming value $\mathrm{I}$ if any dimension is at level 3, 0 otherwise. DI, I3, I3-squared, and I2-squared are ordinal variables. Our explanation is based on algorithms developed by Scalone et al, ${ }^{4}$ Shaw et al, ${ }^{13}$ and Badia et al. ${ }^{14}$

Abbreviations: A/D, anxiety/depression; EQ-5D-3L index, EuroQol 5-Dimension 3-Level index; NA, not applicable; P/D, pain/discomfort; S-C, self-care; UA, usual activities.

The three country-specific algorithms differ not only in preference weights derived from individuals' answers but also in the number and type of variables considered in the formulas (Table 1).

In general, in order to calculate utilities, all coefficients are subtracted from 1; the five dimensions (mobility, selfcare, usual activities, pain/discomfort, anxiety/depression) are converted into dummy variables, which assume value 1 if the dimension considered is at level 2 or 3 (depending on the variable considered) and 0 otherwise.

In order to better fit general population's preferences, the formulas also consider additional variables. The UK algorithm includes a dummy variable indicating the presence of "any dimension at level 3" (N3). ${ }^{14}$ The Italian formula includes the "number of dimensions at level 2 or 3 beyond the first" (D1). The US formula considers, besides D1, the "number of dimensions at level 3 beyond the first" (I3), the "square of I3" (I3-squared), and the "square of number of dimensions at level 2 beyond the first" (I2-squared). ${ }^{13}$

\section{Data analysis}

Descriptive statistics (mean, SD, median, minimum [min], maximum $[\max ]$ ) on country-specific utility sets have been calculated.

The strength of the association between EQ-5D-3L index calculated via the Italian, UK, and US utility values - and VAS scores has been investigated by Kendall's tau rank correlation coefficients. ${ }^{15}$

An ordinary least-square (OLS) regression has been performed in order to assess the effect of a set of predictors on the conditional mean EQ-5D-3L index. As patients were not independent observations, OLS standard errors have been clustered on them.

No imputation procedure was applied for replacing missing values.

Statistical analyses have been conducted using Stata13.1 software (StataCorp LP, College Station, TX, USA).

\section{Results}

\section{Sample characteristics}

Sociodemographic and clinical characteristics of the sample are shown in Table 2.

Patients' mean age was 41.18 years (SD: 13.77 ; median: 41; min: 18 ; max: 84$)$, and a slight male prevalence (50.2\%) was observed. The mean HBI was 10.31 (SD: 3.28; min: 8; max: 39$)$. The great majority of patients $(\mathrm{n}=389 ; 77.8 \%)$ scored an HBI between 8 and 11 and 84 subjects (16.8\%) were between 12 and 16, while the remaining 27 (5.4\%) over 16.

Mean years from CD onset were 2.19 (SD: 4.44). Most patients $(\mathrm{n}=436 ; 87.2 \%)$ had a history of $\mathrm{CD} \leq 5$ years, whereas the disease history was $\geq 26$ years for three patients only $(0.6 \%)$.

Table 3 shows the answers given to the EQ-5D-3L questionnaire. In particular, most of the patients experience more severe limitations regarding $\mathrm{d} 3$ (usual activities), $\mathrm{d} 4$ (pain/discomfort), and d5 (anxiety/depression) rather than d1 (mobility) and d2 (self-care). Table 4 shows the scores given through the VAS. Approximately $75 \%$ of patients gave a score on their perceived health higher than 40 .

\section{Italian, UK, and US utility sets}

Figure 1 shows utility values associated with each one of the 62 health states that occurred in the sample. The maximum utility value $(1$, ie, perfect health state $[11,111])$ obviously overlaps, irrespective of the algorithm adopted. Conversely, the minimum utility value drops to $-0.26,-0.48$, and -0.04 when applying Italian, UK, and US weights, respectively. In 
Table 2 Sociodemographic and clinical characteristics of the patients' sample $(n=500)$

\begin{tabular}{|c|c|}
\hline Characteristics & Number (\%) of patients \\
\hline \multicolumn{2}{|l|}{ Sex } \\
\hline Males & $25 \mathrm{I}(50.2)$ \\
\hline Females & $249(49.8)$ \\
\hline Age $($ mean $\pm S D)$ & $41.18 \pm 13.77$ \\
\hline $18-24$ years & $52(10.4)$ \\
\hline $25-34$ years & $132(26.4)$ \\
\hline $35-44$ years & $112(22.4)$ \\
\hline $45-54$ years & $114(22.8)$ \\
\hline $55-64$ years & $62(12.4)$ \\
\hline $65-74$ years & $21(4.2)$ \\
\hline$\geq 75$ years & $7(1.4)$ \\
\hline \multicolumn{2}{|l|}{ Geographical location } \\
\hline North & $118(23.6)$ \\
\hline Center & $156(31.2)$ \\
\hline South & $226(45.2)$ \\
\hline \multicolumn{2}{|l|}{ Marital status } \\
\hline Single & I82 (36.4) \\
\hline Married & $254(50.8)$ \\
\hline Partnered & $26(5.2)$ \\
\hline Divorced/separated & $29(5.8)$ \\
\hline Widow & $9(1.8)$ \\
\hline \multicolumn{2}{|l|}{ Housing status } \\
\hline With family & $434(86.8)$ \\
\hline Alone & $52(10.4)$ \\
\hline Others & $14(2.8)$ \\
\hline \multicolumn{2}{|l|}{ Education } \\
\hline Elementary school diploma & $33(6.6)$ \\
\hline Secondary school diploma & $130(26.0)$ \\
\hline High school diploma & $263(52.6)$ \\
\hline Degree & $64(12.8)$ \\
\hline Post-degree & $10(2.0)$ \\
\hline \multicolumn{2}{|l|}{ Occupational status } \\
\hline Student & $42(8.4)$ \\
\hline Employed & $27 \mid(54.2)$ \\
\hline Unemployed & $7 \mid(\mid 4.2)$ \\
\hline Housework & $72(14.4)$ \\
\hline Retired & $44(8.8)$ \\
\hline \multicolumn{2}{|l|}{ Caregiver } \\
\hline Yes & $80(16.0)$ \\
\hline No & $420(84.0)$ \\
\hline \multicolumn{2}{|l|}{ Co-payment exemption } \\
\hline Yes & $40 \mathrm{I}(80.2)$ \\
\hline No & $9(1.8)$ \\
\hline Years from CD onset (mean $\pm S D)^{a}$ & $2.19 \pm 4.44$ \\
\hline $0-5$ & $436(87.2)$ \\
\hline $6-10$ & $40(8.0)$ \\
\hline $11-15$ & $15(3.0)$ \\
\hline $16-20$ & $2(0.4)$ \\
\hline $21-25$ & $4(0.8)$ \\
\hline$\geq 26$ & $3(0.6)$ \\
\hline $\mathrm{HBI}($ mean $\pm \mathrm{SD})$ & $10.31 \pm 3.28$ \\
\hline $8-11$ & $389(77.8)$ \\
\hline $12-16$ & $84(16.8)$ \\
\hline$>16$ & $27(5.4)$ \\
\hline
\end{tabular}

Note: ${ }^{2}$ No patient had a disease history lasting from 26 years to 35 years. Abbreviations: CD, Crohn's disease; HBI, Harvey Bradshaw Index.
Table 3 EQ-5D-3L questionnaire results of the patients sample $(\mathrm{N}=500)$

\begin{tabular}{ll}
\hline Dimension & Number of observations (\%) \\
\hline dI: Mobility & \\
Level I & $332(66.4)$ \\
Level 2 & $155(31.0)$ \\
Level 3 & $13(2.6)$ \\
d2: Self-care & \\
Level I & $422(84.4)$ \\
Level 2 & $76(15.2)$ \\
Level 3 & $2(0.4)$ \\
d3: Usual activities & \\
Level I & $195(39.0)$ \\
Level 2 & $265(53.0)$ \\
Level 3 & $40(8.0)$ \\
d4: Pain/Discomfort & \\
Level I & $67(13.4)$ \\
Level 2 & $355(7 I .0)$ \\
Level 3 & $78(15.6)$ \\
d5: Anxiety/Depression & \\
Level I & $183(36.6)$ \\
Level 2 & $263(52.6)$ \\
Level 3 & $54(10.8)$ \\
\hline
\end{tabular}

Notes: Level I =No problems; Level 2 =some problems; Level 3 =severe problems. Abbreviation: EQ-5D-3L index, EuroQol 5-Dimension 3-Level index.

the Italian and US models, the lowest utility score refers to the health state 33332 (severe problems related to mobility, self-care, usual activities, and pain/discomfort, and moderate problems regarding anxiety/depression), whereas in the UK formula it is associated with the health state 32333 . These findings may suggest that, other things being equal, Italian and US people consider a deficiency in their self-care abilities worse than anxiety/depression (and vice versa for UK population).

\section{Statistical analysis}

Table 5 presents the descriptive statistics for EQ-5D-3L index according to the country-specific formula adopted. The highest mean utility value occurs when Italian weights

Table 4 VAS results of the patients sample $(\mathrm{N}=497)^{\mathrm{a}}$

\begin{tabular}{ll}
\hline VAS score & Number of observations (\%) \\
\hline $0-10$ & $25(5.0)$ \\
$1 I-20$ & $2 I(4.2)$ \\
$2 I-30$ & $28(5.6)$ \\
$3 I-40$ & $50(10.1)$ \\
$4 I-50$ & $10 I(20.3)$ \\
$5 I-60$ & $87(17.6)$ \\
$6 I-70$ & $90(18.1)$ \\
$7 I-80$ & $65(13.1)$ \\
$8 I-90$ & $24(4.8)$ \\
$9 \mid-100$ & $6(1.2)$ \\
\hline
\end{tabular}

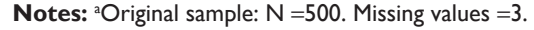

Abbreviation: VAS, Visual Analog Scale. 
Table 5 Descriptive statistics of EQ-5D-3L index using Italian, UK, and US preference weights

\begin{tabular}{|c|c|c|c|c|}
\hline Sample & Mean (SD) & Median & Min & Max \\
\hline \multicolumn{5}{|c|}{ Total sample $(n=500)$} \\
\hline Italian set & $0.76(0.20)$ & 0.81 & -0.26 & 1.00 \\
\hline UK set & $0.57(0.32)$ & 0.69 & -0.48 & 1.00 \\
\hline US set & $0.69(0.22)$ & 0.77 & -0.03 & 1.00 \\
\hline \multicolumn{5}{|c|}{ Patients' HBI: 8-II (n=389) } \\
\hline Italian set & $0.80(0.15)$ & 0.83 & -0.26 & 1.00 \\
\hline UK set & $0.63(0.28)$ & 0.69 & -0.43 & 1.00 \\
\hline US set & $0.72(0.19)$ & 0.78 & -0.04 & 1.00 \\
\hline \multicolumn{5}{|c|}{ Patients' HBI: I2-I6 (n=84) } \\
\hline Italian set & $0.68(0.26)$ & 0.78 & -0.19 & 1.00 \\
\hline UK set & $0.45(0.37)$ & 0.62 & -0.48 & 1.00 \\
\hline US set & $0.60(0.24)$ & 0.71 & -0.03 & 1.00 \\
\hline \multicolumn{5}{|c|}{ Patients' HBI: > I6 (n=27) } \\
\hline Italian set & $0.52(0.32)$ & 0.57 & -0.19 & 0.91 \\
\hline UK set & $0.22(0.40)$ & 0.16 & -0.48 & 0.85 \\
\hline US set & $0.45(0.28)$ & 0.44 & -0.03 & 0.84 \\
\hline
\end{tabular}

Abbreviations: EQ-5D-3L index, EuroQol 5-Dimension 3-Level index; HBI Harvey Bradshaw Index; Min, minimum; Max, maximum.

are applied (mean: 0.76; SD: 0.20; median: 0.81; min: -0.26 ; max: 1.00), followed by US (mean: 0.69; SD: 0.22 ; median: 0.77; min: -0.04 ; max: 1.00 ) and UK ones (mean: 0.58 ; SD: 0.32; median: 0.69; min: -0.48 ; max: 1.00 ).

All the three value distributions are left-skewed (mean $<$ median), as mean values are dragged down by low scores associated with the most severe health states (ie, three or four levels equal to 3 ).

Considering the 62 health states that occurred in the sample, Italian utilities are always higher than UK utilities with the exclusion of the perfect health state where both are equal to 1 (Figure 1). US utilities are generally lower than Italian ones and higher than UK utilities. However, US utilities become higher than Italian ones in correspondence of a group of eight severe health states $(31233,31331,32231,32232,32233$, 32332,32333 , and 33332). UK values assume a negative sign much more frequently and, when it happens, their magnitude is also higher than in the Italian and US sets.

When using Italian preference weights, the great majority $(89.8 \%)$ of health values fall in the range between 0.50 and 1.00 , while only $1.6 \%$ of the scores are negative utilities. Conversely, $75 \%$ of UK values fall in the range between 0.50 and 1.00 , and $8.8 \%$ of the observations present a negative utility value. US utilities distribution is similar to the Italian one, despite having more utilities falling in the range $0.00-0.50(18 \%)$ and fewer negative values (1\%).

Finally, the distance between the curves, considered in pairs, increases as the health states become worse (ie, they are characterized by the prevalence of levels 2 and 3 in the five dimensions).

Mean EQ VAS scores equal 58.50 (SD: 18.72; median: 60; range: $0-100$ ) when HBI is between 8 and 11 , and 42.57 (SD: 21.35; median: 49; range: 0-80) when HBI is between 12 and 16. Patients with HBI $>16$ express a mean EQ VAS score of 29.96 (SD: 21.88; median: 30; range: 0-90).

Consistently with the existing literature, ${ }^{16}$ VAS scores given by respondents tend to be multiples of 5 (347/508, or $69.29 \%)$ or $10(273 / 508$, or $54.60 \%)$.

Finally, a ceiling effect for EQ-5D-3L index has been shown. ${ }^{17,18}$ EQ-5D-3L index reached 1.00 (ie, no problems in any of the five dimensions) for $7 \%$ of the sample (35 out of 500 responders), whereas the percentage of patients reporting full health dramatically drops to $0.4 \%$ (two out of 497 responders) for EQ VAS score.

Due to missing values, the correlation between EQ-5D-3L index and EQ VAS score has been studied in 497 patients only (Table 6).

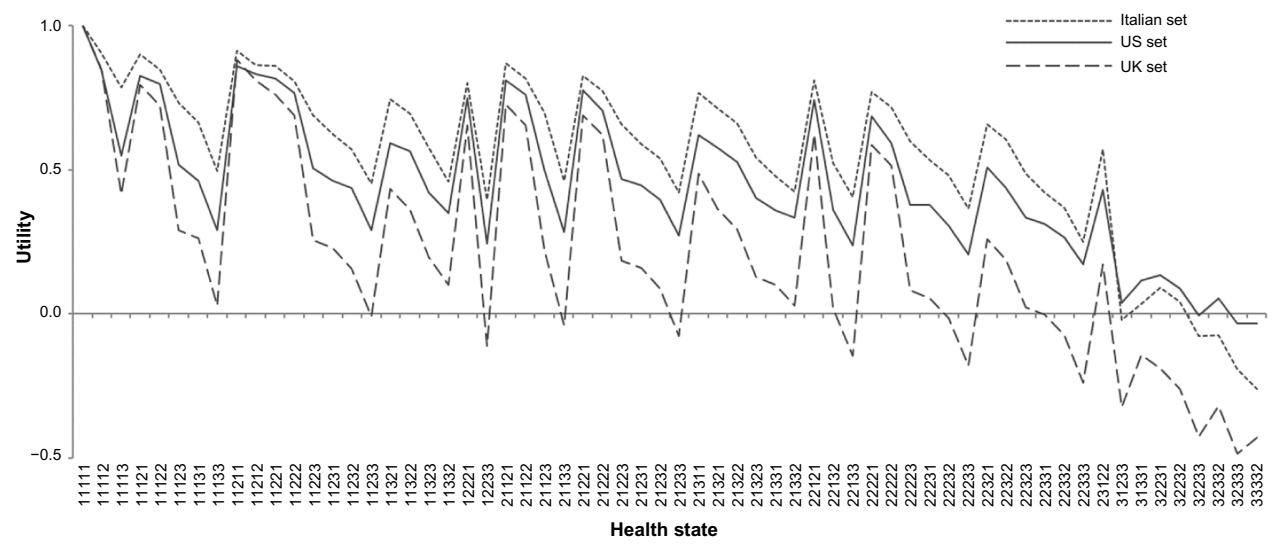

Figure I Italian, UK, and US value sets per health state $(n=62)$ occurred in the sample.

Notes: The health states are ranked in decreasing order according to the utility values of the Italian set. 
Table 6 Rank correlation between EQ-5D-3L index and EQ VAS

\begin{tabular}{llll}
\hline Set type & Kendall's tau-a & Kendall's tau-b & $P$-value \\
\hline Italian set $(n=497)$ & 0.449 & 0.448 & $<0.000$ I \\
UK set $(n=497)$ & 0.445 & 0.474 & $<0.000$ I \\
US set $(n=497)$ & 0.445 & 0.475 & $<0.000$ I \\
\hline
\end{tabular}

Note: $P$-values hold for both Kendall's tau-a and Kendall's tau-b.

Abbreviations: EQ-5D-3L index, EuroQol 5-Dimension 3-Level index; EQ VAS, EuroQol Visual Analog Scale.

Regardless of the tariff sets, Kendall's tau rank correlation coefficients show a positive (and highly statistically significant; $P<0.0001)$ association between the two EQ instruments meaning that the higher the EQ-5D-3L index, the higher the EQ VAS score related to the same health state (and vice versa).

Other things being equal, OLS results show that mean conditional EQ-5D-3L index for patients with HBI 8-11 is higher when calculated with the Italian set vs both UK $(+0.17$; $P<0.0001)$ and US $(+0.07 ; P<0.0001)$ ones (Table 7).

Moreover, a country-specific main effect in favor of the Italian utility weights was found for baseline HBI level (8-11). When the EQ-5D-3L index was calculated on the grounds of the UK and US tariffs, the predicted difference

Table 7 Ordinary least-square regression

\begin{tabular}{|c|c|c|c|}
\hline Predictors & Coefficient & $\begin{array}{l}\text { Cluster- } \\
\text { robust } \\
\mathrm{SE}^{\mathrm{a}}\end{array}$ & $P$-value \\
\hline \multicolumn{4}{|l|}{$\mathrm{HBI}$ (reference category $=8-1 \mathrm{I}$ ) } \\
\hline $12-16$ & -0.114 & 0.029 & $<0.0001$ \\
\hline$>16$ & -0.265 & 0.061 & $<0.0001$ \\
\hline \multicolumn{4}{|l|}{ Country (reference category = Italy) } \\
\hline UK & -0.172 & 0.007 & $<0.0001$ \\
\hline US & -0.073 & 0.003 & $<0.0001$ \\
\hline \multicolumn{4}{|l|}{$\mathrm{HBI} \times$ country } \\
\hline $12-16 \times U K$ & -0.058 & 0.017 & 0.001 \\
\hline $12-16 \times$ US & -0.003 & 0.008 & 0.766 \\
\hline$>16 \times$ UK & -0.135 & 0.031 & $<0.0001$ \\
\hline$>16 \times$ US & -0.005 & 0.018 & 0.785 \\
\hline \multicolumn{4}{|l|}{ Sex (reference category = female) } \\
\hline Male & 0.061 & 0.020 & 0.003 \\
\hline Constant & 0.766 & 0.012 & $<0.0001$ \\
\hline Number of observations & $\mathrm{I}, 500$ & & \\
\hline$R^{2}$ & 0.209 & & \\
\hline$F(9,499)$ & 120.94 & & \\
\hline Prob $>F$ & 0.0000 & & \\
\hline Omitted variable bias $F(3,1,487)$ & 0.64 & & \\
\hline Prob $>F$ & 0.586 & & \\
\hline
\end{tabular}

Notes: Dependent variable: EQ-5D-3L index. ${ }^{\text {SSE }}$ adjusted for 500 clusters in patients.

Abbreviations: EQ-5D-3L index, EuroQol 5-Dimension 3-Level index; HBI, Harvey Bradshaw Index; SE, standard error; Prob, probability. vs the Italian ones reaches $-0.172(P<0.0001)$ and -0.073 $(P<0.0001)$, respectively.

As expected, for all the tariff sets considered, when adjusted for the other predictors, increased HBI reduces mean conditional EQ-5D-3L index.

Others things being equal, when the Italian utility weights were considered, an increase in HBI from 8-11 to 9-16 predicts a variation of $-0.114(P<0.0001)$ in mean conditional EQ-5D-3L index; the predicted decrease in EQ-5D-3L index is more than doubled $(-0.265 ; P<0.0001)$ if HBI worsens from $8-11$ to $>16$. Interestingly, there is also a statistical significant interaction between the UK utility set and both the HBI categories different from the reference one, whereas this finding does not hold for US tariffs.

Eventually, when contrasted against female, ceteris paribus males are predicted a higher mean conditional EQ-5D-3L index $(+0.06 ; P=0.003)$.

\section{Discussion}

To the best of our knowledge, this is the first study that examines the differences between Italian, UK, and US EQ-5D-3L preference weights on a patient's sample.

Results reveal remarkable differences among the three national tariff sets (especially when severe health states occur) suggesting the need for country-specific preference weights when evaluating health-related utilities. ${ }^{4,14,19,20}$ This also leads to the question of which preference weights should be used in cost-effectiveness analyses in those countries where a national utility set is not available yet.

Interestingly, results show that people tend to judge their health state in a more negative way when using the EQ VAS compared to the EQ-5D-3L index. This effect is known as "end-point aversion," a measurement bias that occurs when people are not likely to use the extreme ends of the scales, compromising the integrity of the measurement itself. ${ }^{21}$

Conversely, unlike EQ-5D-3L index, which allows for disutilities in extremely severe health states, the minimum EQ VAS score is zero; as a consequence, health states perceived as worse than death do not have a proper representation on the EQ VAS.

Hence, understanding the functioning of these instruments for the measurement of HRQoL is vital for policy-makers in order to make evidence-based and thoughtful decisions in health care planning and resource allocation.

It is also noteworthy that, other things being equal, HBI remarkably affects EQ-5D-3L index differences for patients with $\mathrm{CD}$, especially when UK weights were applied. Hence, 
when adopting a given national set of EQ-5D weights for QALYs calculation, policy-makers should be aware of possible multiplicative effects on the predicted mean conditional EQ-5D-3L index played by disease-specific features and country-specific tariff set.

The results from this study need to be interpreted in the light of some limitations. First of all, the old version of EQ-5D questionnaire was administered to patients with $\mathrm{CD}$, as the new five-level version (EQ-5D-5L) was not available at the time the SOLE study started out. In addition, we considered a convenience sample of patients with moderateto-severe $\mathrm{CD}(\mathrm{HBI} \geq 8)$, which is not representative of the entire CD population.

A third issue relates to the fact that the EQ-5D-3L results in this study were calculated for patients with CD; hence, they cannot be generalized to other patient populations. However, methodological issues regarding the calculation of utilities attached to each health state occurred in the sample can be generalized to other diseases.

As a fourth limitation, some concerns arise around the validity of the EQ instruments to estimate HRQoL in patients with $\mathrm{CD} .^{22}$ Since $\mathrm{CD}$ is a cyclical medical condition that alternates between periods of activity and remission, ${ }^{10}$ questionnaire results may vary according to the disease status respondents are living at that moment. Moreover, people who have experienced a certain health state for a longer time tend to evaluate their HRQoL in a more positive way than those just hit by the disease. ${ }^{23}$ In addition, patients undergoing surgery might have a different perception of their HRQoL due to either physical or psychological distress related to the intervention and depending on the outcome of the procedure. ${ }^{24}$ These adaptation-related issues ${ }^{25}$ might have influenced the answers of the sampled individuals, and thus, the study results.

General population weights on samples with a specific condition have been tested by several authors in different contexts. ${ }^{26}$ However, some authors claim the need for patientspecific preference weights when considering particular health conditions. ${ }^{27}$ Since $\mathrm{CD}$-specific preference weights are not available at present, disease-unspecific weights derived from general population have been used in this study.

Obviously, the process of developing disease-specific weights is very time- and resource consuming.

Thus, it would be interesting to compare national tariff sets for at least the most frequent diseases (eg, cancer and cardiovascular diseases) in order to widen the applicability of this approach. For instance, specific weights for inflammatory bowel disease might be applied to both $\mathrm{CD}$ and ulcerative colitis patients. At the same time, the use of disease-specific tariffs would reduce the comparability of health outcomes (ie, QALYs) across different therapeutic areas.

The scope of this study was to compare three tariff sets for the EQ-5D-3L descriptive system. However, it would be interesting to correlate the results of this study with those achievable from other generic health utility instruments such as the Short-Form $36^{28}$ or disease-specific HRQoL questionnaires (ie, the Rating Form of Inflammatory Bowel Disease Patient Concerns). ${ }^{29}$

Finally, more research is needed to explore the impact of clinical and sociodemographic variables, as well as cultural differences, on the country-specific utility sets and to investigate the real causes of the divergence of national value sets.

\section{Conclusion}

This study shows remarkable differences among healthrelated utilities calculated by using Italian, UK, and US EQ-5D-3L preference weights in a patient's sample. These differences can potentially influence QALYs via HRQoL calculation and, ultimately, cost-effectiveness analyses results.

The results provided in this paper suggest the need for using country-specific weights when conducting costeffectiveness analyses, which can be problematic since they have not been calculated for every country. Moreover, given that the EQ-5D questionnaire is currently one of the most adopted methods to measure the HRQoL, ${ }^{1,2}$ national sets of tariffs are particularly important when considering critical medical conditions, since differences among models tend to increase when severe health states occur.

Given the potential differences explained above, others things being equal, rationing choices concerning the introduction of an innovative medical technology in a given country may end up with different decisions on allocation of resources, conditional on the applied preference weights set. This consideration is valid for all countries for which, like Italy until few years ago, national preference weights have not been calculated and, thus, EQ-5D sets elicited from other countries have been used. Hence, the risk of crosscountry health disparities and equity issues concerning the availability of innovative medical technologies cannot be safely ignored.

However, more research is needed to actually quantify the real impact on cost-effectiveness analyses based on the use of different EQ-5D tariffs.

\section{Acknowledgment}

The SOLE study was sponsored by AbbVie. 


\section{Disclosure}

AbbVie contributed to the study design, research, and interpretation of data and writing, reviewing, and approving the publication. VT and MB are employees of AbbVie. CL is a consultant in AbbVie. AbbVie has a contract with Centre for Research on Health and Social Care Management for consultancies. No payments were made for drafting or reviewing this publication. All authors have accepted direct responsibility for the paper. The authors report no other conflicts of interest in this work.

\section{References}

1. Stamuli E. Health outcomes in economic evaluation: who should value health? Br Med Bull. 2001;97(1):197-210.

2. EuroQol Group. EuroQol-a new facility for the measurement of health-related quality of life. Health Policy. 1990;16(3):199-208.

3. Drummond MF, Sculpher MJ, Torrance GW, O’Brien BJ, Stoddart GL. Methods for the Economic Evaluation of Health Care Programmes. 3rd ed. Oxford: Oxford University Press; 2005.

4. Scalone L, Cortesi PA, Ciampichini R, et al. Italian population-based values of EQ-5D health states. Value Health. 2013;16(5):814-822.

5. EuroQol Group [webpage on the Internet]. Measuring Self-Reported Population Health: An International Perspective Based on EQ-5D. [Report on the Internet]. 2004:115. [cited September 10, 2015]. Available from: http://www.euroqol.org/fileadmin/user_upload/Documenten/ PDF/Books/Measuring_Self-Reported_Population_Health_-_An_ International_Perspective_based_on_EQ-5D.pdf. Accessed March 17, 2016.

6. Karlsson JA, Nilsson JA, Neovius M, et al. National EQ-5D tariffs and quality-adjusted life-years estimation: comparison of UK, US and Danish utilities in south Swedish rheumatoid arthritis patients. Ann Rheum Dis. 2011;70(12):2163-2166.

7. Galante J, Augustovski F, Colantonio L, et al. Estimation and comparison of EQ-5D health states' utility weights for pneumococcal and human papillomavirus diseases in Argentina, Chile, and the United Kingdom. Value Health. 2011;14(5):60-64.

8. Sakthong P, Charoenvisuthiwongs R, Shabunthom R. A comparison of EQ-5D index scores using the UK, US, and Japan preference weights in a Thai sample with type 2 diabetes. Health Qual Life Outcomes. 2008;6:71-75.

9. Lohr SL. Sampling: Design and Analysis. 2nd ed. Boston: Brooks/Cole; 2010.

10. Benedini V, Caporaso N, Corazza GR, et al. Burden of Crohn's disease: economic and quality of life aspects in Italy. Clinicoecon Outcomes Res. 2012;4:209-218.

11. Soncini M, Triossi O, Leo P, Magni G, RING Study Group. Inflammatory bowel disease and hospital treatment in Italy: the RING multi-centre study. Aliment Pharmacol Ther. 2004;19(1):63-68.
12. Harvey RF, Bradshaw JM. A simple index of Crohn's-disease activity. Lancet. 1980;315(8167):499-556.

13. Shaw JW, Johnson JA, Coons JS. US valuation of EQ-5D health states: development and testing of the D1 valuation model. Med Care. 2005;43(3):203-220.

14. Badia X, Roset M, Herdman M, Kind P. A comparison of United Kingdom and Spanish general population time trade-off values for EQ-5D Health States. Med Decis Making. 2001;21(1):7-16.

15. Kendall M. A new measure of rank correlation. Biometrika. 1938; 30(1-2):81-89

16. Jensen MP, Turner JA, Romano JM. What is the maximum number of levels needed in pain intensity measurement? Pain. 1994;58(3): 387-392.

17. Janssen MF, Pickard AS, Golicki D, et al. Measurement properties of EQ-5D-5L compared to the EQ-5D-3L across eight patient groups: a multi-country study. Qual Life Res. 2013;22(7):1717-1727.

18. Brazier J, Ratcliffe J, Salomon JA, Tsuchiya A. Measuring and Valuing Health Benefits for Economic Evaluation. 1st ed. Oxford: Oxford University Press; 2007.

19. Huang IC, Willke RJ, Atkinson MJ, Lenderking WR, Frangakis C, $\mathrm{Wu} \mathrm{AW}$. US and UK versions of the EQ-5D preference weights: does choice of preference weights make a difference? Qual Life Res. 2007;16(6):1065-1072.

20. Wu YQ, Liu K, Tang X, et al. Empirical research of measuring elderly health utility in the outskirts of Beijing by using European quality of Life 5-dimensions. Beijing Da Xue Xиe Bao. 2012;44(3):397-402.

21. Lee SW, Niileksela CR. Ecobehavioral Consultation in Schools. 1 st ed. New York: Routledge; 2014.

22. König HH, Ulshöfer A, Gregor M, et al. Validation of the EuroQol questionnaire in patients with inflammatory bowel disease. Eur $J$ Gastroenterol Hepatol. 2002;14(11):1205-1215.

23. Jansen SJ, Kievit J, Nooij MA, Stiggelbout AM. Stability of patients' preferences for chemotherapy: the impact of experience. Med Decis Making. 2001;21(4):295-306.

24. McLeod RS, Baxter NN. Quality of life of patients with inflammatory bowel disease after surgery. World J Surg. 1998;22(4):375-381.

25. Schwartz B. The Paradox of Choice: Why More is Less. 1st ed. New York: Harper Perennial; 2004.

26. Balaban DJ, Sagi PC, Goldfarb NI, Nettler S. Weights for scoring the quality of well-being (QWB) instrument among rheumatoid arthritis: a comparison to general population weights. Med Care. 1986;24(11):973-980.

27. Pickard AS, Ray S, Ganguli A, Cella D. Comparison of FACT- and EQ5D-based utility scores in cancer. Value Health. 2012;15(2):305-311.

28. Ware JE Jr, Sherbourne CD. The MOS 36-item short-form health survey (SF-36): I. Conceptual framework and item selection. Med Care. 1992;30(6):473-483.

29. Hjortswang H, Strom M, Almeida RT, Almer S. Evaluation of the RFIPC, a disease-specific health-related quality of life questionnaire, in Swedish patients with ulcerative colitis. Scand J Gastroenterol. 1997;32(12):1235-1240.
ClinicoEconomics and Outcomes Research

\section{Publish your work in this journal}

ClinicoEconomics \& Outcomes Research is an international, peerreviewed open-access journal focusing on Health Technology Assessment, Pharmacoeconomics and Outcomes Research in the areas of diagnosis, medical devices, and clinical, surgical and pharmacological intervention. The economic impact of health policy and health systems

\section{Dovepress}

organization also constitute important areas of coverage. The manuscript management system is completely online and includes a very quick and fair peer-review system, which is all easy to use. Visit http://www.dovepress.com/testimonials.php to read real quotes from published authors. 